\title{
Reduction in packed bed of iron ore and coal under one-dimensional heating: experimental results and modelling
}

\author{
T. Coetsee ${ }^{1}$ and P. C. Pistorius*2
}

\begin{abstract}
Packed beds of coal and iron ore (mostly in the size range 425-850 $\mu \mathrm{m}$ ) were heated by thermal radiation to the bed surface, to test possible rate determining steps, the effect of coal volatiles, and whether the previously predicted near constant and approximately linear relationship between heat transfer and reduction holds. Bed depths were mostly $40 \mathrm{~mm}$ and $16 \mathrm{~mm}$ in some cases. The results confirm that coal volatiles contribute significantly to reduction, reducing the bed temperature slightly, decreasing the energy requirement for reduction, and increasing the extent of reduction. A one-dimensional heat transfer and reaction rate model suggests that the thermal conductivity through reacted layers is higher than predicted, likely by the formation of continuous metal paths and of openings which support radiative heat transfer.
\end{abstract}

Keywords: Carbothermic reduction, Coal volatiles, Heat transfer control

\section{Introduction}

Solid-state reduction of iron ore fines with coal as reductant is of interest in the development of several ironmaking processes, including the Ifcon process. ${ }^{1}$ Given the highly endothermic nature of carbon based reduction, and the low thermal conductivity of a packed bed of ore and coal, study of the kinetics of this type of process requires quantification of the rate of heat transfer to the packed bed, and of temperature differences within the packed bed. A companion paper ${ }^{2}$ described the development of an experimental rig and sample splitting system which allows such measurements. In this paper, experimental results are presented for reduction of hematite ore fines (three different size fractions) with coal (three different size fractions, with prior removal of the volatile matter by charring in some cases). The packed bed (mixture of ore and coal) was heated one-dimensionally by radiation, using a bed depth of $40 \mathrm{~mm}$ in most cases. This heating mode was expected to yield a combination of radiative and conductive heat transfer control; furnace temperatures were 1300,1400 and $1500^{\circ} \mathrm{C}$. Over this range of furnace temperatures both the reduction and gasification reactions (which occur within the packed bed at temperatures which are substantially lower than the furnace temperature) were expected to be limiting. The choice of conditions leading to this complex combination of heat transfer control and chemical reaction control was deliberate: the choice reflects the practical conditions

\footnotetext{
${ }^{1}$ Exxaro Resources, PO box 9229, Pretoria 0001, South Africa

${ }^{2}$ Department of Materials Science and Engineering, Carnegie, Mellon University, Pittsburgh PA 15213, USA, (both workers were in the Department of Materials Science and Engineering, University of Pretoria at the time the work was carried out)

*Corresponding author, email pistorius@cmu.edu
}

in coal based solid-state reduction of iron oxide, and also serves to test the suggestion that, despite complex kinetics, an approximately linear relationship between the rate of heat transfer and the rate of reduction is expected. This linear relationship was predicted earlier, based on modelling studies. ${ }^{3}$

The experimental results are compared with predictions of the one-dimensional model previously developed for reduction in iron oxide carbon pellets. ${ }^{4}$

\section{Experimental}

\section{Raw materials}

Iron ore fines and coal, both from South African mines, were used in the experiments. Different size ranges were prepared by screening. In addition, char was prepared from the coal by devolatilisation under inert conditions. The chemical analyses of the different size fractions of iron ore and reductant are given in Tables 1 and 2. (Note that the analysis of the iron ore in Table 1 does not add up to $100 \%$ because the iron is present as $\mathrm{Fe}_{2} \mathrm{O}_{3}$, which is reported as total $\mathrm{Fe}$ in the table.)

In preparing the packed bed samples, a molar ratio of fixed carbon to reducible oxygen in ore of 0.97 was used ('reducible oxygen' is here taken to be the oxygen bound as $\mathrm{Fe}_{2} \mathrm{O}_{3}$ in the iron ore). This meant that each kilogram of coal-ore mixture contained $0.24 \mathrm{~kg}$ coal and $0.76 \mathrm{~kg}$ ore.

\section{Reduction conditions and analysis}

The experimental approach has been described in detail elsewhere, ${ }^{2,5}$ and is hence summarised briefly here. Packed bed samples were contained in a cylindrical insulating crucible (cut from fibreboard), with internal dimensions of $30 \mathrm{~mm}$ diameter and $40 \mathrm{~mm}$ depth. A packed bed thickness of $40 \mathrm{~mm}$ was used as basis, and a 
Table 1 Chemical composition of different size ranges of hematite ore fines, mass-\%

\begin{tabular}{lrrr}
\hline & $\begin{array}{l}-425 \text { to } \\
+300 \mu \mathrm{m}\end{array}$ & $\begin{array}{c}-850 \text { to } \\
+425 \mu \mathrm{m}\end{array}$ & $\begin{array}{r}-2000 \\
+1400 \mu \mathrm{m}\end{array}$ \\
\hline $\mathrm{Al}_{2} \mathrm{O}_{3}$ & 1.35 & 1.64 & 1.35 \\
$\mathrm{CaO}$ & 0.25 & 0.19 & 0.25 \\
$\mathrm{Cr}$ & $<0.05$ & $<0.05$ & $<0.05$ \\
$\mathrm{Fe}$ (total) & 63.5 & 63.0 & 63.5 \\
$\mathrm{~K}{ }_{2} \mathrm{O}$ & 0.20 & 0.23 & 0.20 \\
$\mathrm{MgO}$ & 0.08 & 0.05 & 0.08 \\
$\mathrm{MnO}$ & 0.03 & 0.04 & 0.03 \\
$\mathrm{Ni}$ & $<0.05$ & $<0.05$ & $<0.05$ \\
$\mathrm{P}$ & 0.05 & 0.05 & 0.05 \\
$\mathrm{SiO}$ & 3.43 & 3.95 & 3.43 \\
$\mathrm{C}$ & 0.03 & 0.01 & 0.03 \\
$\mathrm{~S}$ & 0.01 & 0.02 & 0.01 \\
$\mathrm{Ba}$ & $<0.05$ & 0.49 & $<0.05$ \\
$\mathrm{TiO}_{2}$ & 0.06 & 0.10 & 0.06 \\
$\mathrm{Moisture}$ & 0.02 & 0.01 & 0.02 \\
\hline
\end{tabular}

series with $16 \mathrm{~mm}$ material layer thickness was tested for comparison. The sample was heated by radiation to the upper sample surface. The sample was placed with its upper surface below the hot zone of a vertical tube furnace. The rate of radiative heat transfer to the sample was calculated from measured temperatures at the sample surface, and at three positions along the working tube of the furnace. The sample surface temperature was measured by pyrometer, and temperatures within the sample were measured with thermocouples placed 4,10 , 20 and $30 \mathrm{~mm}$ below the sample surface. After reaction, the sample was cooled by lowering it away from the hot zone; after cooling the sample was divided into three horizontal sections for chemical analysis. The extent of reduction was determined (for each section) by quantifying the distribution of iron between different valencies, by wet chemical analysis. Argon was flowed through the furnace as carrier gas. The product gas was analysed for Ar, $\mathrm{CO}, \mathrm{CO}_{2}, \mathrm{H}_{2}$ and $\mathrm{CH}_{4}$ with a quadrupole mass spectrometer and $\mathrm{H}_{2} \mathrm{O}$ was analysed with a chilled mirror hygrometer. The offgas analysis was used to monitor the experiment, and not to quantify the extent of reduction. This was because coal contains a significant content of bound oxygen, which was released a part of the volatile matter throughout the experiment, contributing to the $\mathrm{CO}, \mathrm{CO}_{2}$ and $\mathrm{H}_{2} \mathrm{O}$ in the offgas. It was not possible to distinguish between oxygen from coal, and oxygen from reduction, in the offgas. For this reason, the offgas analysis could not be used to quantify the reduction extent, and the chemical analysis of the sample (iron and its oxides) was used instead. For the experiments performed with char (devolatilised coal), comparison between the results of the offgas analysis and those of chemical analysis was possible; the offgas analysis indicated a slightly higher degree of reduction than found from chemical analysis, with the difference ranging from 3 to $7 \%$.

\section{Modelling}

The one-dimensional model as described previously ${ }^{4}$ was used. The previous model was for spherical pellets; this was adapted for a constant cross-section area, with radiative heat transfer occurs to one sample surface, and the other boundary of the sample is an insulating and impervious surface. Conductive heat transfer occurs within the sample. The thermal conductivity is predicted from the sample composition, porosity and temperature, using expressions from the literature. ${ }^{6}$ Shrinkage was not taken into account; shrinkage was not expected to play a large role $^{7}$ (although, as the results presented later show, shrinkage did appear to enhance heat transfer into the sample). To calculate the vertical temperature profile, the sample was divided into 20 horizontal nodes, and a finite difference method was used to calculate the rate of conductive heat transfer. As discussed later, the literature expressions for thermal conductivity led to under prediction of the temperatures within the sample interior. In these preliminary calculations, the predicted thermal conductivity was increased by a constant factor for better correspondence with measured values; this factor was 4 . The factor 4 was based on comparison between the experimental values and model predictions, of bed temperatures, degree of reduction and heat transferred to the sample; the value of 4 was the smallest multiplication factor that gave reasonable agreement between the experimental data and model predictions. As discussed later, all predicted thermal conductivity values were low even after applying the factor 4 increase, being less than $2 \mathrm{~W} \mathrm{~m}^{-1} \mathrm{~K}^{-1}$ in all cases.

The rate of radiative transfer to the upper surface of the sample was taken to follow the simple expression

$$
q=\sigma \varepsilon A\left(T_{\mathrm{f}}^{4}-T_{\mathrm{p}}^{4}\right)
$$

where $q$ is the rate of heat transfer (W), $\sigma$ is the StefanBoltzmann constant, $\varepsilon$ is the material mixture emissivity (taken to be 0.9 ), $A$ is the horizontal area the sample, $T_{\mathrm{f}}$ is the furnace temperature and $T_{\mathrm{p}}$ is the material layer surface temperature.

The change in temperature of each node at the end of each time interval was found with the explicit finite difference approach. The same expressions for enthalpies and thermal conductivities were used as before. ${ }^{4}$

The only chemical reactions occurring in the sample were taken to be stepwise reduction of hematite to magnetite to wüstite and then to iron (by $\mathrm{CO}$ and $\mathrm{H}_{2}$ in parallel) (reduction of magnetite to iron below $570^{\circ} \mathrm{C}$ ), together with carbon gasification (by both the Boudouard and the water-gas reactions).

Solution of carbon in the iron was not taken into account. The role of gangue and ash during reduction

Table 2 Chemical composition of different size ranges of coal, mass-\%

\begin{tabular}{|c|c|c|c|c|c|c|c|c|c|}
\hline \multirow[b]{2}{*}{ Reductant } & \multicolumn{4}{|c|}{ Proximate analysis (air dried basis) } & \multicolumn{5}{|c|}{ Ultimate analysis (dry basis) } \\
\hline & Moisture & Ash & Volatiles & Fixed Carbon & $\% \mathrm{C}$ & $\% \mathrm{H}$ & $\% \mathrm{~N}$ & $\% \mathrm{O}$ & $\% \mathrm{~S}$ \\
\hline Coal $(-425$ to $+300 \mu \mathrm{m})$ & $3 \cdot 2$ & $12 \cdot 0$ & $22 \cdot 8$ & $62 \cdot 0$ & $76 \cdot 0$ & $3 \cdot 60$ & $1 \cdot 80$ & $5 \cdot 72$ & $0 \cdot 36$ \\
\hline Coal $(-850$ to $+425 \mu \mathrm{m})$ & $3 \cdot 3$ & $12 \cdot 0$ & $22 \cdot 5$ & $62 \cdot 2$ & $75 \cdot 9$ & 3.53 & $1 \cdot 81$ & $6 \cdot 03$ & $0 \cdot 36$ \\
\hline Coal $(-2000$ to $+1400 \mu \mathrm{m})$ & $3 \cdot 2$ & $12 \cdot 0$ & $22 \cdot 8$ & $62 \cdot 0$ & $76 \cdot 0$ & $3 \cdot 60$ & $1 \cdot 80$ & $5 \cdot 72$ & $0 \cdot 36$ \\
\hline Char $(-850$ to $+425 \mu \mathrm{m})$ & $4 \cdot 0$ & $17 \cdot 3$ & 1.9 & $77 \cdot 5$ & $78 \cdot 9$ & $0 \cdot 26$ & 0.60 & $2 \cdot 64$ & $0 \cdot 31$ \\
\hline
\end{tabular}


Table 3 Rate constants used in model calculations

\begin{tabular}{|c|c|c|}
\hline Reaction & $\mathrm{k}_{\mathrm{o}} \mathrm{kg}^{-1} \mathrm{~s}^{-1}$ & $\begin{array}{l}E_{\mathrm{A}} \\
\mathrm{J} \mathrm{mol}^{-1}\end{array}$ \\
\hline $3 \mathrm{Fe}_{2} \mathrm{O}_{3}+\mathrm{CO}=2 \mathrm{Fe}_{3} \mathrm{O}_{4}+\mathrm{CO}_{2}$ & 0.07099 & 33141 \\
\hline $3 \mathrm{Fe}_{2} \mathrm{O}_{3}+\mathrm{H}_{2}=2 \mathrm{Fe}_{3} \mathrm{O}_{4}+\mathrm{H}_{2} \mathrm{O}$ & 1720 & 85759 \\
\hline $\begin{array}{l}\mathrm{Fe}_{3} \mathrm{O}_{4}+\mathrm{CO}=3 \mathrm{FeO}+\mathrm{CO}_{2} \\
\left(\text { above } 570^{\circ} \mathrm{C}\right)\end{array}$ & $0 \cdot 77428$ & 52929 \\
\hline $\begin{array}{l}\mathrm{Fe}_{3} \mathrm{O}_{4}+\mathrm{H}_{2}=3 \mathrm{FeO}+\mathrm{H}_{2} \mathrm{O} \\
\left(\text { above } 570^{\circ} \mathrm{C} \text { ) }\right.\end{array}$ & 135 & 56980 \\
\hline $\begin{array}{l}\mathrm{FeO}+\mathrm{CO}=\mathrm{Fe}+\mathrm{CO}_{2} \\
\left(\text { above } 570^{\circ} \mathrm{C}\right)\end{array}$ & 0.58452 & 51337 \\
\hline $\begin{array}{l}\mathrm{FeO}+\mathrm{H}_{2}=\mathrm{Fe}+\mathrm{H}_{2} \mathrm{O} \\
\left(\text { above } 570^{\circ} \mathrm{C} \text { ) }\right.\end{array}$ & 18.051 & 56569 \\
\hline $\begin{array}{l}0 \cdot 25 \mathrm{Fe}_{3} \mathrm{O}_{4}+\mathrm{CO}=0 \cdot 75 \mathrm{Fe}+\mathrm{CO}_{2} \\
\text { (below } 570^{\circ} \mathrm{C} \text { ) }\end{array}$ & 0.07099 & 33141 \\
\hline $\begin{array}{l}0.25 \mathrm{Fe}_{3} \mathrm{O}_{4}+\mathrm{H}_{2}=0.75 \mathrm{Fe}+\mathrm{H}_{2} \mathrm{O} \\
\text { (below } 570^{\circ} \mathrm{C} \text { ) }\end{array}$ & 1720 & 85759 \\
\hline $\mathrm{CO}_{2}+\mathrm{C}=2 \mathrm{CO}$ & $618 \cdot 0$ & 137098 \\
\hline $\mathrm{H}_{2} \mathrm{O}+\mathrm{C}=\mathrm{CO}+\mathrm{H}_{2}$ & $207 \cdot 7$ & 130889 \\
\hline Devolatilisation & $k, s^{-1}$ & $E_{\mathrm{A}}, \mathrm{J} \mathrm{mol}^{-1}$ \\
\hline First step & $1.81 \times 10^{5}$ & 74000 \\
\hline Second step & $8.99 \times 10^{8}$ & 157000 \\
\hline
\end{tabular}

was neglected. The argon carrier gas was taken into account in the enthalpy calculations, assuming that the argon gas was heated from room temperature to the sample surface temperature.

Given the small coal and oxide particle sizes, reaction rates were assumed to be independent of particle size, and first order with respect to all reactants. The rate expressions were hence as follows

\section{Reduction rate (moles of $\mathrm{O}$ removed per unit time)}

$$
=k_{\mathrm{R}} M_{\mathrm{Fe}}(1-F)\left(p_{\mathrm{i}}-p_{\mathrm{i}}^{\text {equilib }}\right) / R T
$$

where $k_{\mathrm{R}}$ is the reduction rate constant $\left(\mathrm{m}^{3} \mathrm{~s}^{-1} \mathrm{~kg}^{-1}\right)$, $M_{\mathrm{Fe}}$ is the mass of $\mathrm{Fe}$ per bed volume $\left(\mathrm{kg} \mathrm{m}^{-3}\right), F$ is the degree of reduction, $p_{\mathrm{i}}$ is the partial pressure of reductant $i\left(\mathrm{H}_{2}\right.$ or $\left.\mathrm{CO}\right)(\mathrm{Pa}), p_{\mathrm{i}}^{\text {equilib }}$ is the equilibrium partial pressure of the reductant, $R$ is the ideal gas constant and $T$ is the absolute temperature.

\section{Boudouard reaction rate}

(in moles of $\mathrm{C}$ gasified per unit time)

$$
=k_{\mathrm{B}} M_{\mathrm{C}}\left(p_{\mathrm{CO}_{2}}-p_{\mathrm{CO}_{2}}{ }^{\text {equilib }}\right) / R T
$$

where $k_{\mathrm{B}}$ is the Boudouard reaction rate constant $\left(\mathrm{m}^{3} \mathrm{~s}^{-1} \mathrm{~kg}^{-1}\right), M_{\mathrm{C}}$ is the mass of fixed carbon per mass of iron in the material mixture (in $\mathrm{kg} \mathrm{C}$ per $\mathrm{kg} \mathrm{Fe}$ ), $p_{\mathrm{CO} 2}$ is the partial pressure of reductant $\mathrm{CO}_{2}(\mathrm{~Pa})$, and $p_{\mathrm{CO} 2}{ }^{\text {equilib }}$ is its equilibrium partial pressure.

Water gas reaction rate

(in moles of $\mathrm{C}$ gasified per unit time)

$$
=k_{\mathrm{W}} M_{\mathrm{C}}\left(p_{\mathrm{H} 2 \mathrm{O}}-p_{\mathrm{H} 2 \mathrm{O}}^{\text {equilib }}\right) / R T
$$

Table 4 Default conditions for model calculations

\begin{tabular}{ll}
\hline Parameter & Value \\
\hline Material layer thickness & $0.04 \mathrm{~m}$ \\
$M_{\mathrm{Fe}}$ & $677 \mathrm{~kg} \mathrm{~m}^{-3}$ \\
Initial $M_{\mathrm{C}}$ (fixed carbon) & $0.38 \mathrm{~kg} \mathrm{per} \mathrm{kg} \mathrm{Fe}$ \\
Volatile content (mass volatiles relative & 0.36 \\
to mass fixed carbon) & $1.55 \mathrm{Ndm}^{3} \mathrm{~min}^{-1}$ \\
Argon flow rate &
\end{tabular}
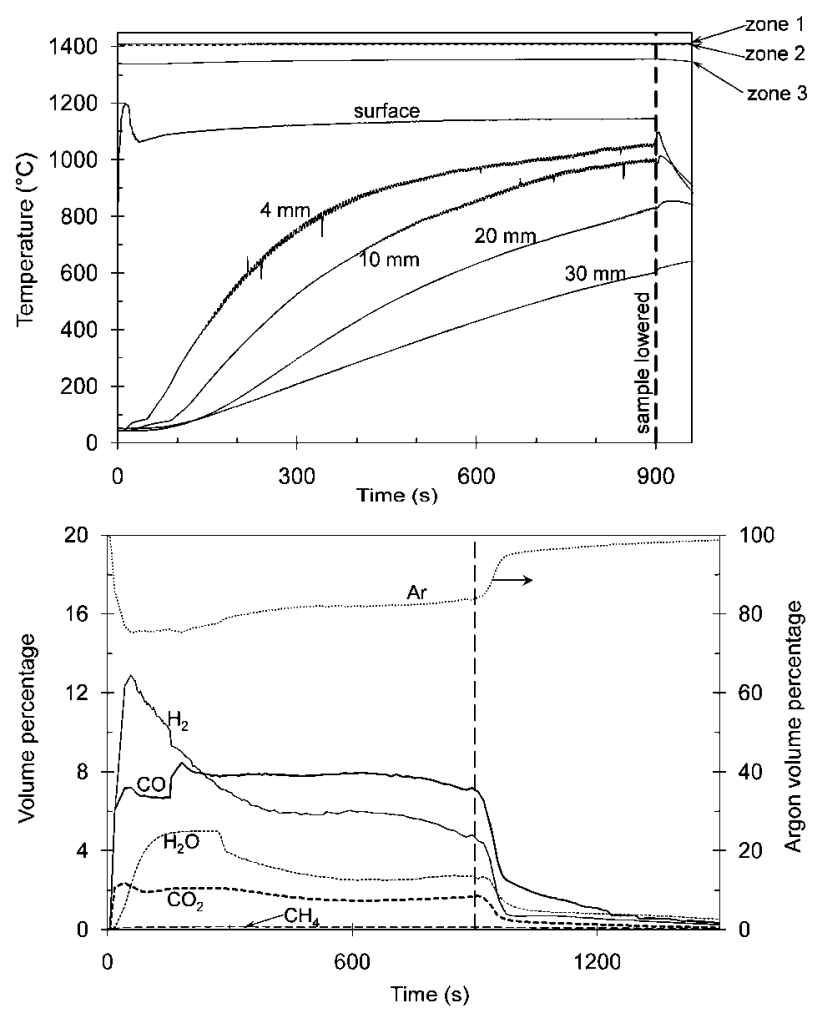

1 Typical measurements during reaction of mixture of iron ore and coal under one-dimensional heating, showing furnace and sample temperatures (upper) and offgas composition (lower): base case mixture of ore and coal; $1400^{\circ} \mathrm{C}$ furnace temperature; $15 \mathrm{~min}$ heating time; bed depth $40 \mathrm{~mm}$

The rate constants were assumed to follow Arrhenius type temperature dependences, with constants as given in Table 3. These constants are experimental values, from a separate project, as measured for the base particle size $(-850$ to $+425 \mu \mathrm{m})$ of the same char and ore fines as used in the experiments reported here.

Following Strezov et al., it was assumed that volatile matter is removed in two steps, as methane; to obtain an upper estimate of the likely effect of the volatile matter, the methane was assumed to crack to carbon (deposited within the material layer) and hydrogen (which can contribute to reduction or escape from the material layer) upon devolatilisation. Each of the two devolatilisation steps was assumed to remove half of the volatile matter, and to be first order with respect to the amount of volatile matter remaining in the coal. The rate constants and activation energies for the two steps are given in Table 3, and were deduced from the data reported by Strezov et al. ${ }^{8}$

Default conditions for the model calculations are listed in Table 4.

\section{Results and discussion}

\section{Rate determining steps}

Typical measurements during reaction of the base case mixture (ore and coal both in the size range 425$850 \mu \mathrm{m})$ at a furnace temperature of $1400^{\circ} \mathrm{C}$ are given in Fig. 1. At time zero, the sample was raised into the reaction position and exposed to thermal radiation from the furnace hot zone; at the end of the reaction period (15 min in this case, and marked by the vertical broken 

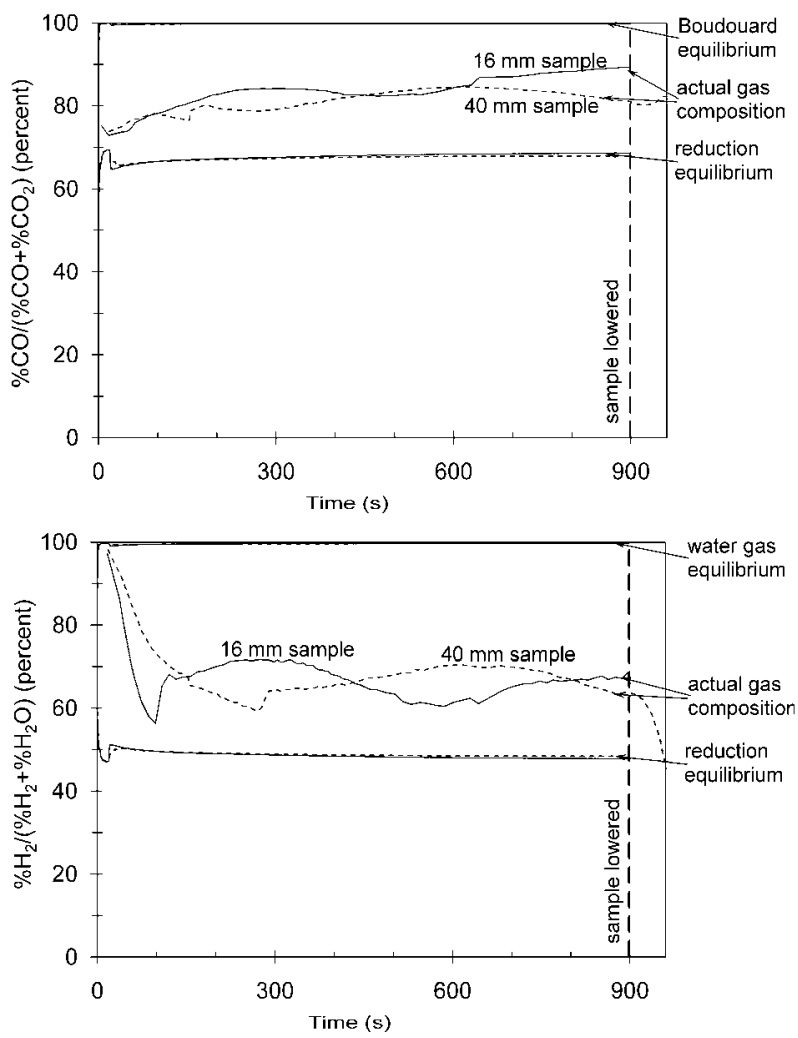

2 Comparison of offgas compositions relative to equilibria of reduction and gasification reactions, for $\mathrm{CO} / \mathrm{CO}_{2}$ (upper), and $\mathrm{H}_{2} / \mathrm{H}_{2} \mathrm{O}$ (lower): equilibria are calculated for sample surface temperature; base case mixture of ore and coal; $1400^{\circ} \mathrm{C}$ furnace temperature; $15 \mathrm{~min}$ heating time; bed depths $16 \mathrm{~mm}$ and $40 \mathrm{~mm}$

line in the graphs of Fig. 1), the sample was lowered again.

The changes in sample temperature and gas evolution are similar to those observed for the simpler case used to test the experimental approach, ${ }^{2}$ where mixtures of prereduced ore and char were reacted. The main difference is the presence of a significant amount of hydrogen and water vapour in the offgas, showing a significant role of coal volatiles in reduction. Another difference is the apparent excursion in sample surface temperature immediately after exposure of the sample to thermal radiation: as Fig. 1 shows, the measured surface temperature peaked at $1200^{\circ} \mathrm{C}(12 \mathrm{~s}$ after the start of the run), decreased to a local minimum at $30 \mathrm{~s}$, and then increased again. This anomalous temperature peak is thought to be an experimental artefact, caused by the rapid evolution of volatiles when heating starts. (This initial temperature excursion was not observed when char was used as reductant instead of coal.) Visual observation of the sample surface through the viewport (normally used for pyrometer measurements) showed a pulse of material visibly released from the sample surface, during this initial period, when using coal. Visibility (and interaction with thermal radiation) was probably caused by the formation of soot in the gas stream above the sample surface (during devolatilisation of the coal close to the sample surface), and this soot interfered with the pyrometer reading. The view to the sample cleared when the measured surface temperature reached the local minimum $(\sim 30 \mathrm{~s})$, and the rest of the pyrometer readings were unaffected.

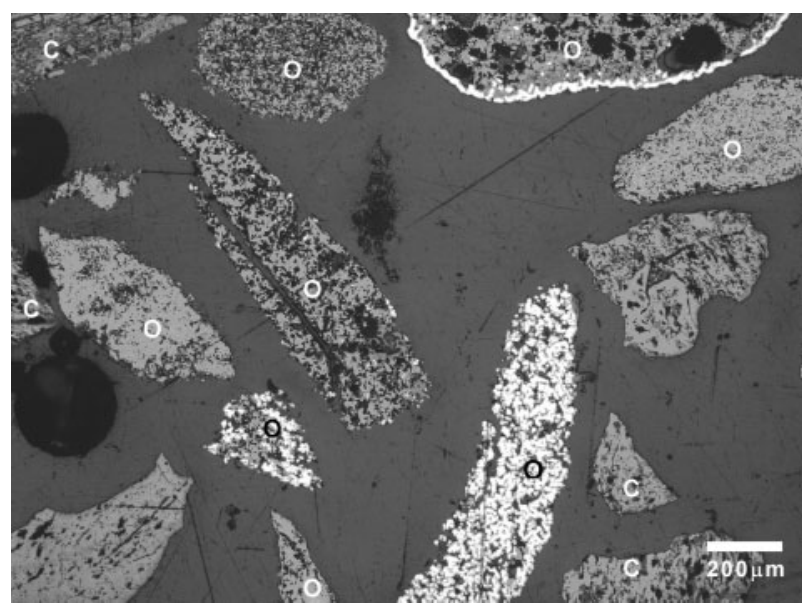

3 Material recovered from the middle layer of a $40 \mathrm{~mm}$ deep sample (base case mixture of ore and coal) after reaction at a $1400^{\circ} \mathrm{C}$ furnace temperature for $15 \mathrm{~min}$. The temperature in the middle layer reached approximately $800^{\circ} \mathrm{C}$ at the end of the reaction period. Particles marked ' $O$ ' are reacted ore particles, and ' $C$ ' coal particles. Bright areas are metallic iron. Reflected light optical micrograph

The conclusion that both radiative and conductive thermal resistances are significant (as found for the reaction of prereduced ore and char) ${ }^{2}$ also holds here: as Fig. 1 shows, there are significant temperature differences between the sample surface and the furnace hot zone (indicating that radiative heat transfer was a limitation), and within the sample itself (showing that conduction into the sample was also limiting). Mixed control also holds for the chemical reactions within the sample; this is shown by Fig. 2, which compares the $\mathrm{CO} /$ $\mathrm{CO}_{2}$ and $\mathrm{H}_{2} / \mathrm{H}_{2} \mathrm{O}$ ratios in the offgas with the equilibrium ratios, for the wüstite reduction reactions $\left(\mathrm{FeO}+\mathrm{CO}=\mathrm{Fe}+\mathrm{CO}_{2}\right.$, and $\left.\mathrm{FeO}+\mathrm{H}_{2}=\mathrm{Fe}+\mathrm{H}_{2} \mathrm{O}\right)$ and gasification reactions (Boudouard reaction, $\mathrm{C}+\mathrm{CO}_{2}=$ $2 \mathrm{CO}$, and water gas reaction, $\mathrm{H}_{2} \mathrm{O}+\mathrm{C}=\mathrm{H}_{2}+\mathrm{CO}$ ); the equilibria were evaluated at the measured surface temperatures. Evidently the actual gas compositions lie between the reduction and gasification equilibria. The heterogeneous nature of the ore particles was reflected in varying degrees of reduction at a given position within the sample (Fig. 3).

\section{Relationship between heat transfer and extent of reduction}

As mentioned earlier, one of the ideas tested with these experimental results is that an approximately linear relationship is expected between the total heat transferred to the sample, and the extent of reduction, despite the complexities of mixed control. In these experiments, the sample surface remained at an approximately constant temperature for reaction times up to $15 \mathrm{~min}$ (the maximum used in these experiments; see Fig. 1). The near constant surface temperature, together with near constant furnace temperatures (Fig. 1), implies an approximately constant radiative heat flux to the sample surface. In line with this, the extent of reduction increased approximately linearly with time (Fig. 4). Figure 4 shows results for sample thicknesses of 16 and $40 \mathrm{~mm}$, and for coal and char as reductants. (Note that the data point for each reaction time and reaction 


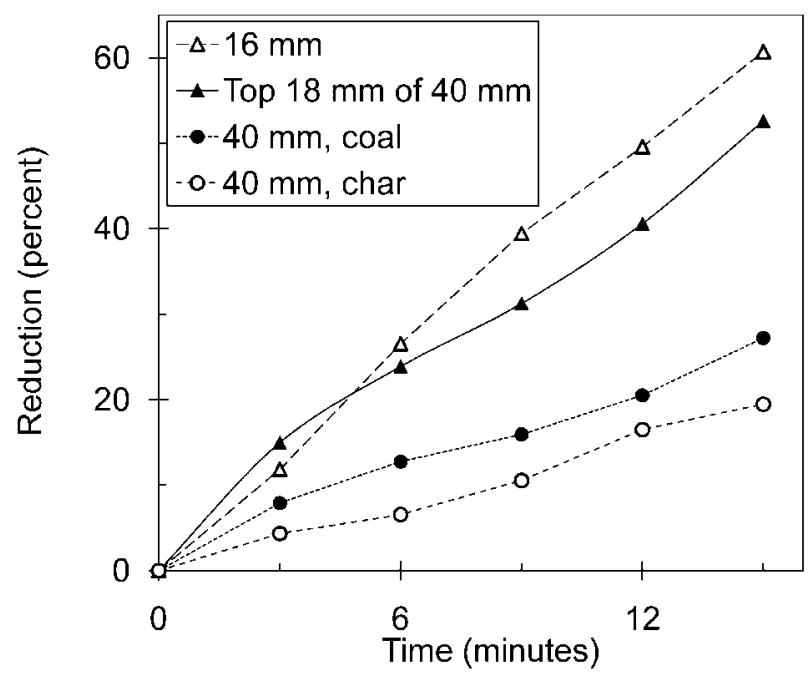

4 Change in extent of reduction of iron oxide with reaction time, for furnace at $1400^{\circ} \mathrm{C}$. Each data point was obtained by analysing a different sample after reaction for $3,6,9,12$ or $15 \mathrm{~min}$. Conditions (except where indicated otherwise): base case mixture of ore and coal, and $40 \mathrm{~mm}$ bed depths. Symbol indicate the following conditions: $\Delta$ - bed depth $16 \mathrm{~mm}$; $\Delta$ - reduction in upper layer (18 $\mathrm{mm}$ thick) of $40 \mathrm{~mm}$ thick sample; - and $\bigcirc$ - overall reduction in full $\mathbf{4 0} \mathrm{mm}$ thick sample, using respectively coal and char as reductants

condition, in this and all subsequent graphs, was obtained from a separate sample, since the degree of reduction was found by chemical analysis of each sample after reaction.) The figure illustrates that the reaction conditions affect the extent of reaction strongly: the thinner sample reacted much further than the thicker sample (emphasising the limiting effect of heat conduction into the sample); coal as reductant gave significantly more reduction than did char prepared from the same coal (confirming the role of volatiles in reduction).

It is interesting to note that the $16 \mathrm{~mm}$ thick sample reacted further than the upper $18 \mathrm{~mm}$ thick portion of a $40 \mathrm{~mm}$ thick sample (Fig. 4). The reason for this appears to be that conduction of heat into the lower parts of the $40 \mathrm{~mm}$ thick sample caused the temperature in its upper region to be lower than in the $16 \mathrm{~mm}$ thick sample. This is shown by the temperature profile through the samples, as measured at the end of the $15 \mathrm{~min}$ reaction period (Fig. 5): whereas the entire $16 \mathrm{~mm}$ thick sample was at essentially the same temperature, the temperature dropped significantly with depth below the surface of the $40 \mathrm{~mm}$ thick sample.

The relationship between heat transfer and reduction is shown more directly in Fig. 6, which plots the total heat transferred to the sample against the degree of reduction (averaged over the sample volume); the relationship is approximately linear, and there is no significant difference in the trend for samples reacted at different furnace temperatures. However, furnace temperature strongly affected the extent of reduction. This can be seen by comparing the extents of reduction in samples reacted for the same length of time at different temperatures. In Fig. 6 the reaction time is given by the number in italics next to each data point, and for each of the five reaction times used here $(3,6,9,12$ and $15 \mathrm{~min})$ the extent of reaction is much greater at the higher

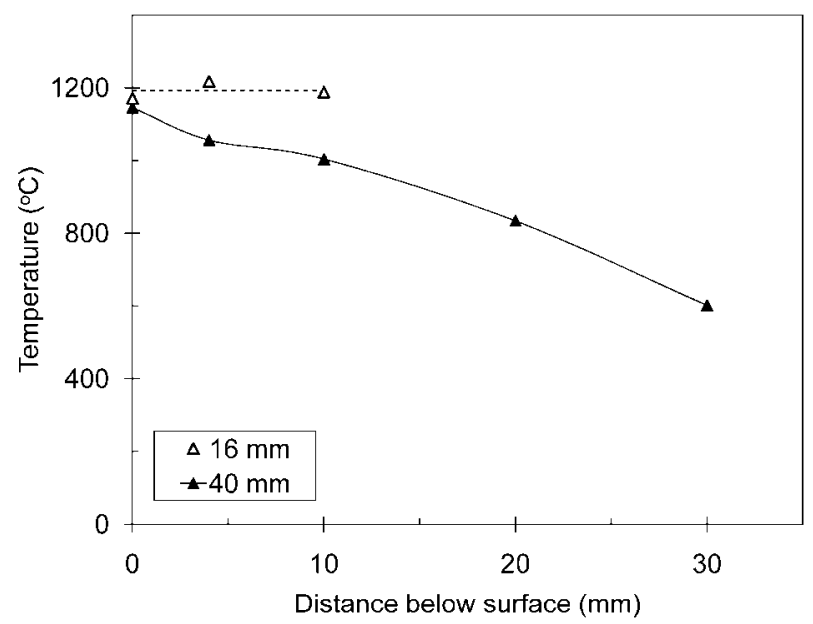

5 Temperature profile through samples of 16 and $40 \mathrm{~mm}$ thickness, after $15 \mathrm{~min}$ reaction at $1400^{\circ} \mathrm{C}$ furnace temperature (base case mixture of ore and coal)

temperatures. (In fact, the observed effect of a higher furnace temperature is stronger than predicted by the model, as discussed later in this paper.)

Use of smaller particles of ore, and separately of coal, did give somewhat higher degrees of reduction, for similar heat transfer (Fig. 6), whereas use of coarser ore or coal particles did not have an effect. The observed effect of fine particles is surprising: while finer particles would have larger chemical reaction rate constants (especially since some ore particles displayed topochemical reaction; see Fig. 3), an effect on the energy requirement is only expected if there is a change in offgas temperature with particle size (since heating of the offgas is a large part of the energy requirements), or if there is some change in composition with particle size The latter was not the case here, as Tables 1 and 2 show, there was little difference in the composition of the different size fractions, for both ore and coal. Also, the

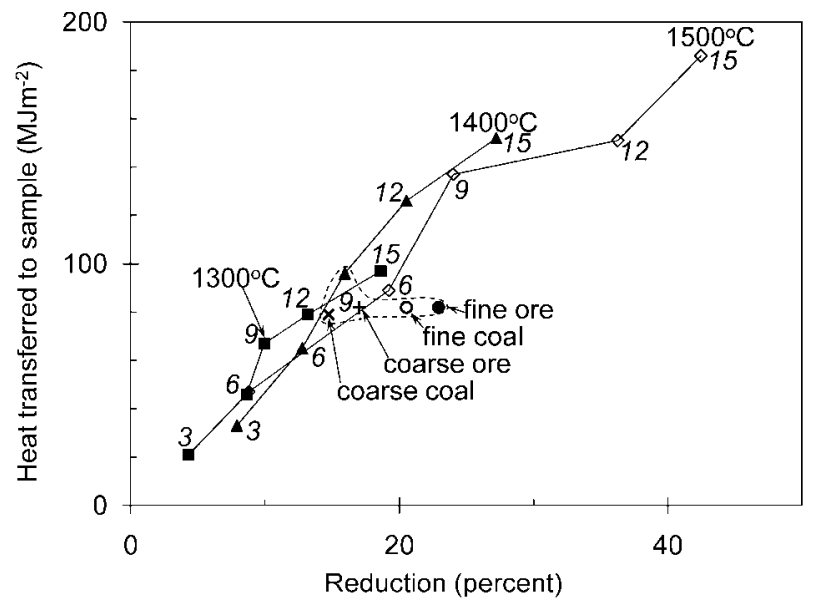

6 Relationship between the total heat transferred to the sample, and the extent of reduction, averaged over the sample. Ore-coal mixtures of standard size, $40 \mathrm{~mm}$ thick, reacted at 1300,1400 and $1500^{\circ} \mathrm{C}$ furnace temperatures. Numbers in italics next to each data point give the reaction time in minutes. Results for four mixtures with different sizes of either coal or ore, reacted for $9 \mathrm{~min}$ at a $1400^{\circ} \mathrm{C}$ furnace temperature, are also shown 


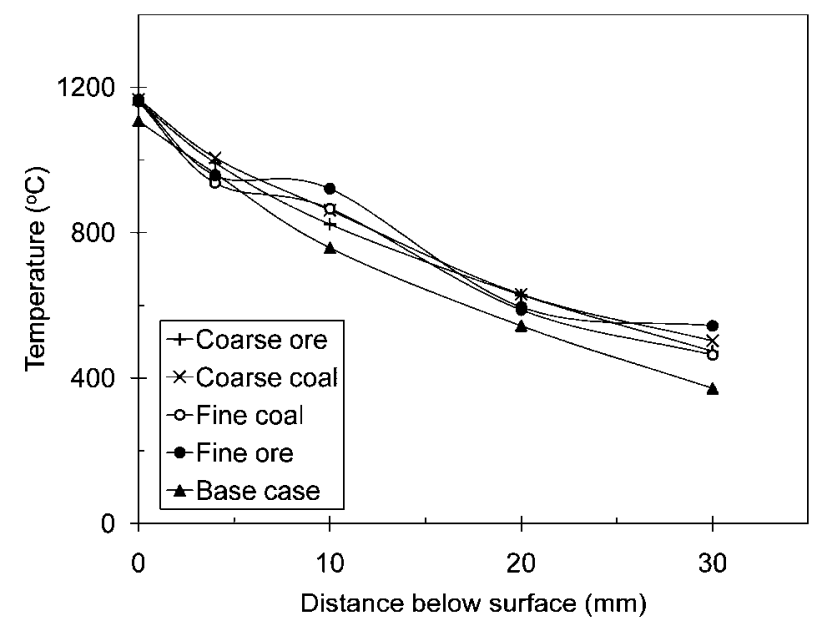

7 Temperature profile through samples of $40 \mathrm{~mm}$ thickness, at end of $9 \mathrm{~min}$ reaction at $1400^{\circ} \mathrm{C}$ furnace temperature, for mixture containing standard sizes of ore and coal ('base case'), and mixtures containing either larger or smaller particles of either coal or ore

bulk densities of the sample mixtures were similar (in the range of 1391 to $1423 \mathrm{~kg} \mathrm{~m}^{-3}$ in all cases). The temperature profile through the sample bed was also similar for feed materials of different sizes (Fig. 7), although there appears to be a slight effect of the finer material giving a lower temperature at a position $4 \mathrm{~mm}$ below the sample surface (which is where much of the reaction is taking place after $9 \mathrm{~min}$ ). This is in accordance with the expectation that more reactive material would tend to give a lower reaction temperature, with the result that the product gas is formed at a lower temperature and hence has a lower sensible heat. However, it is not clear that this can account for the difference in energy requirement apparently shown in Fig. 6, since the offgas should be heated to close to the surface temperature as the offgas rises through the sample, and the surface temperature was essentially the same for the mixtures containing particles of different sizes (Fig. 7). A separate experimental study would be required to resolve the detail of the effect of particle size.

\section{Effect of coal volatiles}

The effect of volatiles in the reaction system was tested by reacting samples containing char instead of coal as reductant, while maintaining the same ratio of fixed carbon to reducible oxygen as in the coal containing mixtures. Reduction is more rapid when coal is used (Fig. 4), and there is also an effect on the energy requirement (Fig. 8). As Fig. 8 shows, the cumulative heat transferred to the sample for each reaction period was slightly smaller for the char containing sample than for the coal containing sample (the reason was that the surface of the char containing sample was at a slightly higher temperature). However, the extent of reduction was substantially less, for each reaction period, when char was used. The net effect is to increase the slope of the curve of heat transferred against degree of reduction (Fig. 8).

Possible reasons for the lowered energy requirement when coal (instead of char) is used as reductant are the enthalpy of the devolatilisation reaction, the heat of the reduction reaction, and differences in offgas

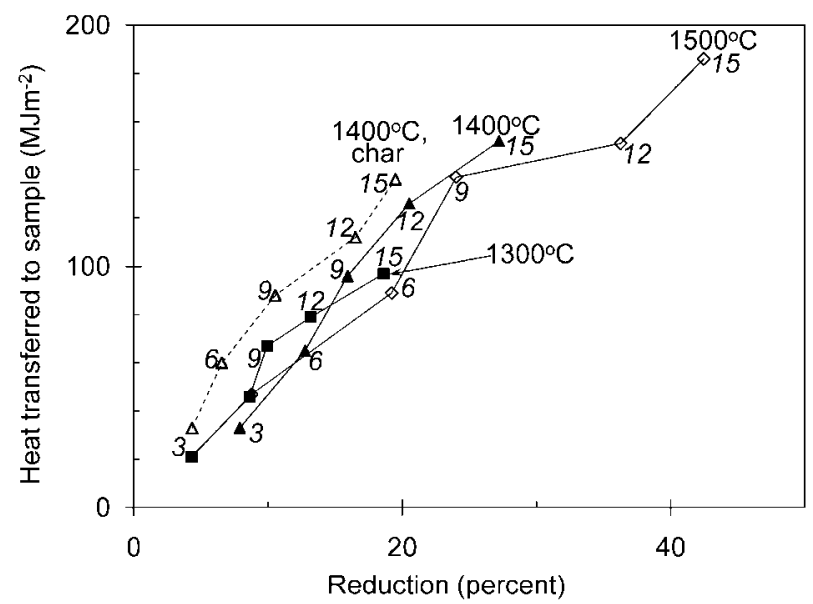

8 Relationship between the total heat transferred to the sample, and the extent of reduction, averaged over the sample. Data as for Fig. 6 , with the addition of the results for ore char mixtures of standard size, $40 \mathrm{~mm}$ deep, reacted at $1400^{\circ} \mathrm{C}$ furnace temperature. Numbers in italics next to each data point give the reaction time in minutes

temperature. Preliminary evaluation of the former two effects is presented below.

Devolatilisation of coal can be exothermic or endothermic, with heats of devolatilisation up to $200 \mathrm{~kJ}$ per $\mathrm{kg}$ of coal. ${ }^{9}$ For mixtures containing a coal mass fraction of 0.24 (ore mass fraction 0.76 ), with a mixture bulk density of $1400 \mathrm{~kg} \mathrm{~m}^{-3}$ and thickness of $40 \mathrm{~mm}$, the heat associated with devolatilisation is hence less than $2.7 \mathrm{MJ} \mathrm{m}^{-2}$, which is much smaller than the difference between the energy requirement for coal based and char based reduction shown in Fig. 8 .

Evaluating differences in the heat of reaction requires knowledge on the form in which volatiles are released. Little methane is found in the offgas when reacting mixtures containing coal (Fig. 1), but this may be the result of reactions between the volatiles and the ore. To test this, mixtures of coal and fine alumina were heated with furnace hot zone temperatures of 1300,1400 and $1500^{\circ} \mathrm{C}$ until negligible volatile content was observed in the product gas analyses. For the coalalumina mixtures the product gas analyses similarly showed that devolatilisation largely released hydrogen, with some $\mathrm{CO}$ and $\mathrm{CO}_{2}$ present at 1400 and $1500^{\circ} \mathrm{C}$ furnace hot zone temperatures; negligible methane was measured in the product gas. The overall reduction reaction by volatiles can hence be approximated as $\mathrm{Fe}_{2} \mathrm{O}_{3}+3 \mathrm{H}_{2}=2 \mathrm{Fe}+3 \mathrm{H}_{2} \mathrm{O}$, which has a heat of reaction of $64 \mathrm{~kJ} \mathrm{~mol}^{-1}$ at $800^{\circ} \mathrm{C}$. In contrast, carbon based reduction $\left(\mathrm{Fe}_{2} \mathrm{O}_{3}+3 \mathrm{C}=2 \mathrm{Fe}+3 \mathrm{CO}\right)$ has a heat of reaction of $472 \mathrm{~kJ} \mathrm{~mol}^{-1}$ at $800^{\circ} \mathrm{C}$. As an upper bound estimate of the effect of this, comparing reduction with $\mathrm{H}_{2}$ only with $\mathrm{C}$ only, and if the $\mathrm{H}_{2} \mathrm{O}$ does not gasify carbon by the water gas reaction, the difference in energy requirement is $408 \mathrm{~kJ} \mathrm{~mol}^{-1}$ for full reduction, or approximately $82 \mathrm{~kJ} \mathrm{~mol}^{-1}$ for $20 \%$ reduction. For the ore mass fraction and mixture bulk density as stated earlier, the latter value implies a difference in energy requirement of $20 \mathrm{MJ} \mathrm{m}^{-2}$, which is of the order of that observed in Fig. 8. However, the unknown extent of the strongly endothermic backreaction of $\mathrm{H}_{2} \mathrm{O}$ with the char (water gas reaction; heat 

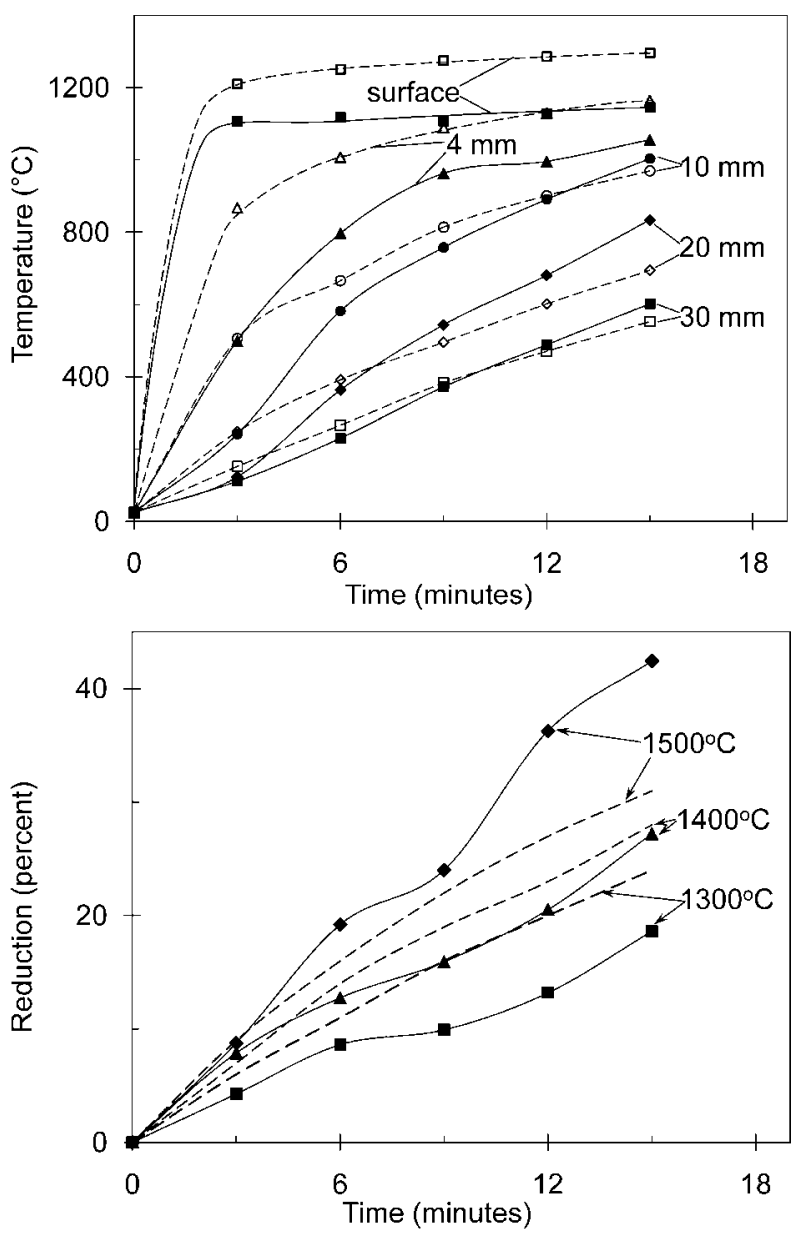

9 Comparison of model predictions (broken lines) with experimental measurements (solid lines and filled symbols) for $40 \mathrm{~mm}$ thick sample, showing temperature changes for reaction at $1400^{\circ} \mathrm{C}$ furnace temperature (upper), and change in extent of reduction with time for samples reacted at three furnace temperatures (lower)

of reaction $136 \mathrm{~kJ}$ per mol $\mathrm{H}_{2} \mathrm{O}$ ) precludes any final conclusion on this.

Despite the current lack of clarity on the fundamental origin of the effect of volatiles, the effects are clearly beneficial, in both increasing the rate of reduction and decreasing the energy requirement for reduction.

\section{Comparison of model predictions with results}

Model predictions of the sample temperatures and degree of reduction are compared with the measured values in Fig. 9. As mentioned earlier, reasonable correspondence between the predicted and measured material layer temperatures, at the end of each reaction period, could only be achieved if the thermal conductivity was increased by a factor of 4 over the value calculated from the literature correlation (the thermal conductivity was low even so, typically ranging from $1.3 \mathrm{~W} \mathrm{~m}^{-1} \mathrm{~K}^{-1}$ for unreduced mixture to $0.7 \mathrm{~W} \mathrm{~m}^{-1} \mathrm{~K}^{-1}$ when reduction proceeded as far as wüstite). As shown in Fig. 9, this approach gave reasonable agreement between the predicted and measured temperatures, although the model overpredicted the temperature at the surface and $4 \mathrm{~mm}$ below the surface. The calculated extent of reduction agreed well with measurements for the $1400^{\circ} \mathrm{C}$ furnace temperature,

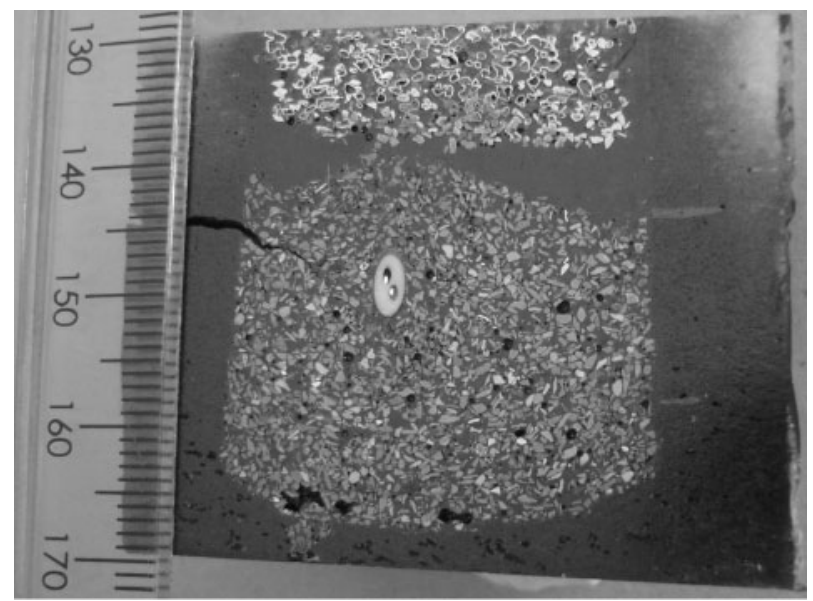

10 Optical macrograph of a polished vertical cross-section through a $40 \mathrm{~mm}$ thick sample (base mixture) after reaction at $1500^{\circ} \mathrm{C}$ furnace temperature for 15 min. Ruler gives distances in millimetres. The white ellipse in the sample centre is part of a thermocouple sheath. Some material was lost during sample removal and mounting, causing the gap approximately $10 \mathrm{~mm}$ below the sample surface

but underpredicted reduction at $1500^{\circ} \mathrm{C}$ and overpredicted at $1300^{\circ} \mathrm{C}$ (Fig. 9).

Given the prominent limiting role of conduction, the differences probably arise from an incomplete description of heat transfer into the reacting sample bed. Possible reasons are the formation of continuous metal paths, and a role of radiative heat transfer into the bed. Figure 10 illustrates the sample features which support these suggestions: a metallic network is formed (from the iron layers which surround partially or fully reduced ore particles), providing a fast heat conduction path into the sample. This is in contrast with the assumed random distribution of material which is the basis of the thermal conductivity correlation which was used in the model. ${ }^{6}$ Openings, at the scale of hundreds of microns, which form in the reacted layer (Fig. 10) may support radiative heat transfer into the sample interior (similar, albeit at a different length scale, to the shrinkage of ore coal pellets upon reduction in the paired straight hearth process, which shrinkage allows radiation to reach the lower layers of pellets); ${ }^{10}$ a role of radiative heat transfer into the bed may account for the larger than expected effect of furnace temperature on reaction rate. The result of both of these would be a larger effective thermal conductivity into the sample, which would give both lower surface temperatures, and higher reaction rates, in line with the experimental data of Fig. 9.

Despite these deviations between the detail of the model predictions and experimental data, the observed and predicted relationships between heat transfer and reduction agree well (Fig. 11).

\section{Conclusions}

For the reaction system considered here, a stagnant bed of mixed ore and coal heated unidirectionally from the top surface, both radiation heat transfer to the bed surface and heat transfer into the bed limit the reaction rate. The limiting effect of conductive heat transfer is demonstrated by significant temperature differences 


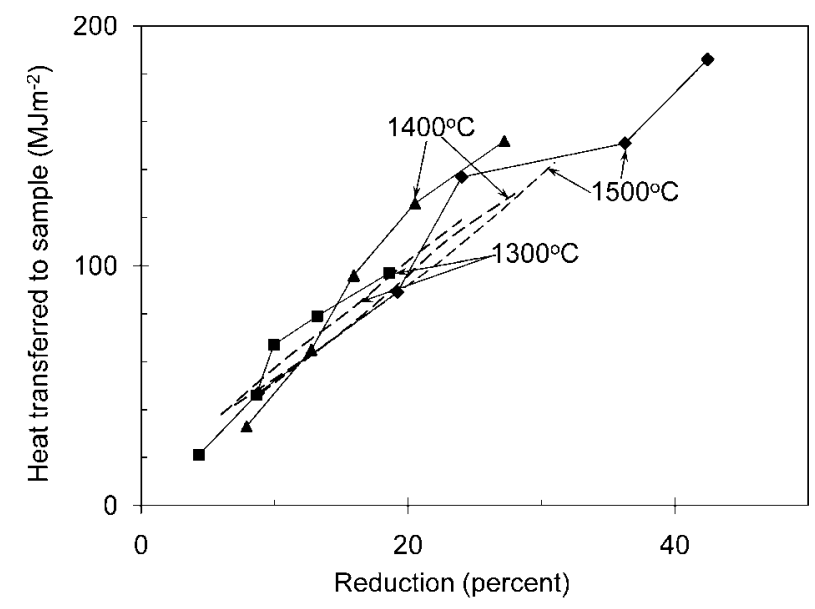

11 Comparison of measured relationship between heat transfer and reduction (symbols and solid lines), with model predictions (broken lines), for $40 \mathrm{~mm}$ thick ore-coal mixtures reacted at different furnace temperatures

within the bed, and more rapid reduction in a thinner bed. Coal volatiles in the form of hydrogen contribute significantly to reduction. The simple mathematical model provides an approximate description of the reaction system, but underestimates the rate of heat transfer through reaction product. For a series of furnace temperatures and raw material sizes, the relationship between the heat transfer and reduction remains largely unchanged.

\section{References}

1. C. P. Manning and R. J. Fruehan: JOM, 2001, 53, (10), 36-43.

2. T. Coetsee and P. C. Pistorius: Ironmaking Steelmaking, doi 10.1179/174328108X393830, to be published.

3. P. C. Pistorius: Scand. J. Metall., 2005, 34, 122-130.

4. T. Coetsee, P. C. Pistorius and E. E. de Villiers: Miner. Eng., 2002, 15, 919-929.

5. T. Coetsee: 'Non-isothermal reaction of iron ore-coal mixtures', $\mathrm{PhD}$ thesis, University of Pretoria, Pretoria, South Africa, 2007.

6. T. Akiyama, H. Ohta, R. Takahashi, Y. Waseda and J. Yagi: ISIJ Int., 1992, 32, 829-837.

7. O. M. Fortini and R. J. Fruehan: Metall. Mater. Trans. B, 2005, 36B, 709-717.

8. V. Strezov, J. A. Lucas and L. Strezov: Metall. Mater. Trans. B, 2000, 31B, 1125-1131.

9. J. Tomeczek and H. Palugniok: Fuel, 1996, 75, 1089-1093.

10. W.-K. Lu and D. Huang: US patent no. 6257879, 2001. 